\title{
COMPARATIVE STUDY OF THE PHYSICOCHEMICAL PROPERTIES AND PHOTOCATALYTIC ACTIVITY OF MODIFIED MCM-41 SYNTHESIZED BY DIRECT (ONE-STEP) INCORPORATION AND IMPREGNATION
}

\author{
Verónica R. Elías, Ema V. Sabre, Sandra G. Casuscelli and Griselda A. Eimer* \\ Centro de Investigación y Tecnología Química (CITeQ), UTN - CONICET, Maestro Marcelo López y Cruz Roja Argentina, Ciudad \\ Universitaria, 5016, Córdoba, Argentina
}

Recebido em 16/09/2015; aceito em 21/01/2016; publicado na web em 12/04/2016

\begin{abstract}
MCM-41 structures were synthesized and modified by direct (one-step) incorporation (DI) and wet impregnation (WI) methods. The solids were characterized by XRF, XRD, $\mathrm{N}_{2}$ adsorption and UV-Vis DR, and catalytically evaluated in the Acid Orange 7 (AO7) degradation under visible light. Significant influence of the presence, dispersion and location of the different $\mathrm{Cr}$ species on photoactivity was evident. Both synthesis methods allowed greater dispersion of the photoactive $\mathrm{Cr}$ species for lower metal content, enhancing efficiency for dye degradation. More specifically, after Ti loading in samples synthesized by DI, a notable AO7 degradation increase was associated with the strong heterojunction between $\mathrm{Ti}$ and $\mathrm{Cr}^{6+}$ species, which wereare highly dispersed due to the DI method used.
\end{abstract}

Keywords: impregnation; direct incorporation; metallic species; photocatalysis.

\section{INTRODUCTION}

In the 90's, M41S transition metal derivatives were extensively studied. In this regard, a variety of metal ions can be introduced in the sieves by different methods to be used as environmentally compatible catalysts for several applications. Particularly, an interesting aim in the last decade was to optimize the use of solar radiation as a clean energy resource for the development of new sustainable pollution abatement technologies. It is known that heterogeneous photocatalytic processes involving semiconductors excitable by solar light have been the focus of numerous investigations. ${ }^{1-5}$ In this sense, the use of different supports for the semiconductor dispersion, such as MCM-41, has emerged as a good strategy to develop new photocatalytic systems. ${ }^{6-17}$ Two methods are usually employed to modify mesoporous molecular sieves with transition metals: direct incorporation (in one step) (DI) ${ }^{18-22}$ and wet impregnation (WI). ${ }^{23-27}$ The introduction of metal ions into the framework is often favored by the DI of the metal source in the synthesis gel. Meanwhile, WI generally allows reaching a larger amount of metallic species (metallic oxides) loaded on the surface. Therefore, these methods lead to different coordination environments of the metal in various metallic species, which gives rise to important differences in the physicochemical properties of the final solids. Thus, these physicochemical properties may be controlled by incorporating metal ions into the framework or loading distinct metallic species such as oxides onto their surface. In this work, we present a comparison between the WI and DI methods to synthesize MCM-41 structures modified with Cr. In addition, these solids were also modified with a second metal, Ti. After Ti loading, the physicochemical properties of both kinds of materials and their photoactivity in Acid Orange 7 (AO7) degradation were evaluated.

\section{EXPERIMENTAL}

\section{Synthesis}

The MCM-41 support was synthesized as previously reported (method B). ${ }^{28}$ The MCM-41 structures were modified with $\mathrm{Cr}$ by two different methods:

\footnotetext{
*e-mail: geimer@scdt.frc.utn.edu.ar
}

WI samples were obtained as reported ${ }^{29-31}$ using several concentrations of $\mathrm{Cr}$ solutions, corresponding to theoretical $\mathrm{Cr}$ loadings of $1.50,3.50$ and $5.00 \mathrm{wt} \%$.

DI samples were obtained as reported $(\operatorname{method} \mathrm{B}),{ }^{28}$ were the $\mathrm{Cr}$ precursor was added to the initial gel (after the TEOS) in order to reach $\mathrm{Si} / \mathrm{Cr}$ molar ratios of 60,40 and 20 (theoretical $\mathrm{Cr}$ loadings of $1.5,2.0$ and $4.5 \mathrm{wt} \%$, respectively). Then, these solids were submitted to desorption and calcination processes already described.$^{28} \mathrm{All}$ solids were modified by $\mathrm{TiO}_{2}$ according to $^{30}$ in order to evaluate the influence of a second metal on their photoactivity. The catalysts were named: $\mathrm{TiO}_{2} / \mathrm{Cr}(\mathrm{DI}) \mathrm{x}$ or $\mathrm{TiO}_{2} / \mathrm{Cr}(\mathrm{WI}) \mathrm{x}$, where DI or WI indicates the method of $\mathrm{Cr}$ incorporation used, $\mathrm{x}$ indicates the theoretical $\mathrm{Cr}$ content (wt\%), and $\mathrm{TiO}_{2}$ is used in the case of the modification with $\mathrm{Ti}$ loading.

\section{Characterization}

The X-ray diffraction (XRD) patterns were recorded in a Philips PW 3830 diffractometer in $2 \theta$ ranges: $1.5-7^{\circ}$ and $20-80^{\circ}$. The mean crystallite size of oxide phases was estimated using Scherrer formulae. ${ }^{32} \mathrm{UV}$-Vis diffuse reflectance spectra (UV-Vis DRS) were recorded using an Optronics OL 750-427 spectrometer between 200 and $900 \mathrm{~nm}$. The $\mathrm{Cr}$ and Ti contents were determined by X-ray fluorescence (XRF) using an Innov-X System model ALPHA-4000. The specific area, the pore size distribution (Dp) and the total pore volume $(\mathrm{Vp})$ were determined from $\mathrm{N}_{2}$ adsorption-desorption isotherms using a Micromeritics ASAP 2010. X-ray photoelectron spectra were collected using a Physical Electronics PHI 5700 spectrometer with non-monochromatic $\mathrm{Mg} \mathrm{K} \alpha$ radiation $(300 \mathrm{~W}, 15 \mathrm{kV}, 1253.6$ $\mathrm{eV}$ ) for the analysis of photo-electronic signals of C $1 s, \mathrm{O} 1 s, \mathrm{Si} 2 p$ and $\mathrm{Cr} 2 p$ and multichannel detector. Spectra of powdered samples were recorded with the constant pass energy values at $29.35 \mathrm{eV}$, using a $720 \mu \mathrm{m}$ diameter analysis area. During data processing of the XPS spectra, binding energy values were referenced to the $\mathrm{C} 1 s$ peak $(284.8$ $\mathrm{eV}$ ) from the adventitious contamination layer.

\section{Catalytic experiments}

Degradation experiments were performed in a photoreactor as was described. ${ }^{30,31,33}$ The suspension volume was $0.5 \mathrm{~L}$ and the 
catalyst concentrations was $1 \mathrm{~g} \mathrm{~L}^{-1}$. Bearing in mind that the $\mathrm{AO} 7$ concentrations from common industrial effluents are in the range of 0.35 and $35 \mathrm{mg} \mathrm{L}^{-1}$, in this work an $\mathrm{AO} 7$ concentration of $20 \mathrm{mg} \mathrm{L}^{-1}$ was chosen. ${ }^{34-38}$ This AO7 concentration corresponds to a $\mathrm{pH}$ of 5 . After reaching the adsorption/desorption equilibrium in the dark, an initial sample was drawn to calculate the initial concentration $\left(\mathrm{C}_{0}\right)$ and the experimental run was started. Each reaction corresponds to $5 \mathrm{~h}$ of irradiation. The AO7 concentration (C) was monitored at $\lambda=485 \mathrm{~nm}$ using a Jasco 7800 spectrophotometer. The AO7 degradation percentage was calculated as $\mathrm{XAO} 7=\left(\mathrm{C}_{0}-\mathrm{C}\right) 100\left(\mathrm{C}_{0}\right)^{-1}$.

\section{RESULTS AND DISCUSSION}

Figures 1 and 2 show the corresponding XRD patterns of the solids. The well-resolved peaks in the low angle region for all samples modified with Cr can be indexed to planes (100), (110) and (200) corresponding to a MCM-41 structure. The half-height width for the first peak would indicate that a higher structural order can be reached by DI, although, in all cases, this ordering decreases slightly with increasing $\mathrm{Cr}$ content. The $\mathrm{Cr}$ incorporation by WI would lead to a higher amount or size of metallic species (oxide clusters or nanoparticles) on the surface, which slightly affects the structural regularity. The high angle XRD patterns show the presence of chromia $\left(2 \theta=33,36,55.2,63\right.$ and $\left.65^{\circ}\right)$ for all $\mathrm{Cr}$ contents in $\mathrm{Cr}(\mathrm{DI}) \mathrm{x}$ samples, and only for the higher $\mathrm{Cr}$ content in samples modified by WI. Nevertheless, a rough estimation of the oxide nanoparticle size showed values of $\sim 48 \mathrm{~nm}$ for the impregnated sample and $\sim 8 \mathrm{~nm}$ for samples synthesized by DI. ${ }^{33}$

Thus, even if the oxide phase appears at lower metal contents for $\mathrm{Cr}(\mathrm{DI}) \mathrm{x}$ samples, these species have a very small size. Besides, the greater size of chromia nanoparticles for $\mathrm{Cr}(\mathrm{WI}) 5$ could contribute to its lower structural regularity. It should be noted that the lack of XRD peaks at high angle does not allow us to discard the presence of oxides in amorphous state or as clusters too small to be detected by XRD. Likewise, XRD patterns of Ti-modified samples (Figure 1S) exhibit peaks corresponding to the presence of anatase $(2 \theta=25,37$, $48,54,55$ and $\left.63^{\circ}\right) .{ }^{31}$

Table 1 lists the physicochemical properties of all samples (see Figure 2S). All solids have high specific areas (typical of MCM-41), which slightly decrease with the $\mathrm{Cr}$ content. Unlike $\mathrm{Cr}(\mathrm{WI}) \mathrm{x}$, the $\mathrm{Cr}(\mathrm{DI}) \mathrm{x}$ samples show a wall thickness $\left(\mathrm{t}_{\mathrm{w}}\right)$ that increases when the $\mathrm{Cr}$ content increases. This fact could be a consequence of the smaller size of the oxide clusters or nanoparticles generated by DI, some of which can be introduced into the mesopores.

Meanwhile, WI would lead to bigger oxide species segregated mainly on the external surface, which could block some mesopores. This feature is evidenced by the lower Vp observed for $\mathrm{Cr}(\mathrm{WI}) \mathrm{x}$ samples, mainly for the higher metal content. Moreover, the higher reduction temperatures observed for DI samples (TPR profiles not shown) would reveal the increased interaction of smaller size chromium species with the support. ${ }^{30}$ This behavior would be due to the high dispersion favored by the direct incorporation method. When
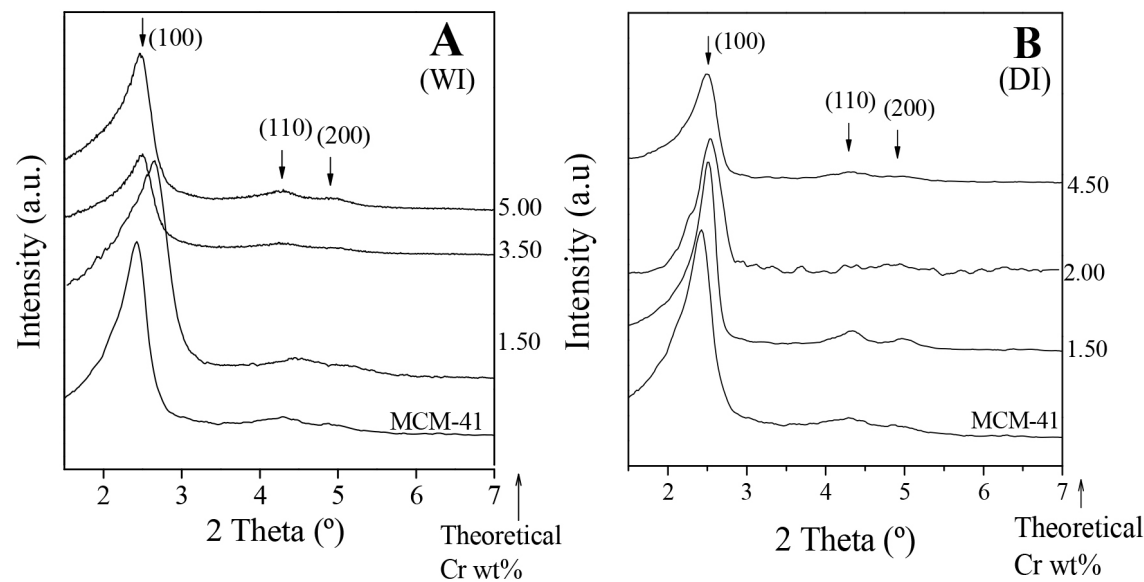

Figure 1. Low-angle XRD patterns of $\boldsymbol{A})$ Samples synthesized by WI and $\boldsymbol{B}$ ) samples synthesized by DI
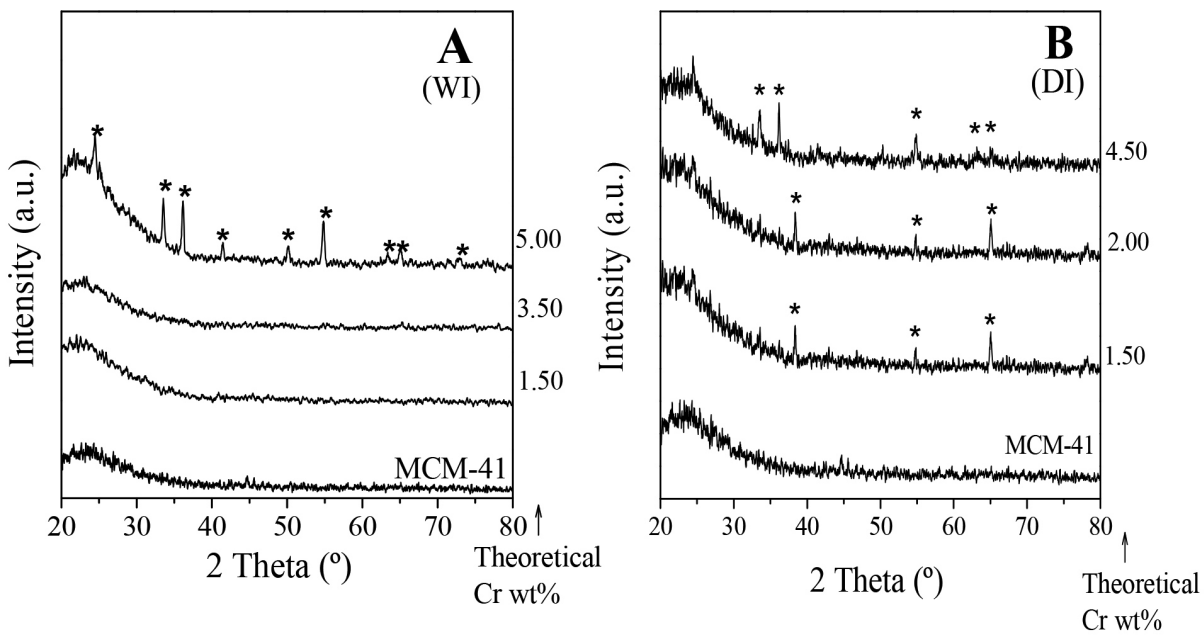

Figure 2. High-angle XRD patterns of $\boldsymbol{A}$ ) Samples synthesized by WI and $\boldsymbol{B}$ ) samples synthesized by DI. (*) $\mathrm{Cr}_{2} \mathrm{O}_{3}$ 
Table 1. Physicochemical properties and Catalytic activity of the synthesized samples

\begin{tabular}{|c|c|c|c|c|c|c|c|c|}
\hline Sample & $\mathrm{Cr}^{\mathrm{a}}$ (wt.\%) & $\mathrm{Ti}(\mathrm{wt} . \%)$ & $a_{0}{ }^{\mathrm{b}}(\mathrm{nm})$ & $\operatorname{Area}^{c}\left(\mathrm{~m}^{2} / g\right)$ & $V \mathbf{p}^{\mathrm{d}}\left(\mathrm{cm}^{3} / \mathrm{g}\right)$ & $\mathrm{Dp}^{\mathrm{e}}(\mathrm{nm})$ & $\mathrm{tw}^{\mathrm{f}}(\mathrm{nm})$ & $\boldsymbol{X}_{\mathrm{AO} 7}$ \\
\hline MCM-41 & - & & 4.20 & 1182 & 1.15 & 2.70 & 1.50 & - \\
\hline $\mathrm{TiO}_{2} / \mathrm{MCM}-4$ & - & 21.73 & 4.08 & 849 & 0.80 & 2.60 & 1.48 & 9.50 \\
\hline $\mathrm{Cr}(\mathrm{WI}) 1.5$ & 0.89 & - & 4.02 & 1093 & 0.86 & 2.55 & 1.47 & 38.42 \\
\hline $\mathrm{Cr}(\mathrm{WI}) 3.5$ & 2.05 & - & 3.87 & 1071 & 0.86 & 2.52 & 1.35 & 67.36 \\
\hline $\mathrm{Cr}(\mathrm{WI}) 5.0$ & 2.89 & - & 4.08 & 1045 & 0.84 & 2.63 & 1.45 & 69.29 \\
\hline $\mathrm{TiO}_{2} / \mathrm{Cr}(\mathrm{WI}) 1.5$ & 0.55 & 21.71 & 4.23 & 662 & 0.56 & 2.59 & 1.64 & 63.34 \\
\hline $\mathrm{TiO}_{2} / \mathrm{Cr}(\mathrm{WI}) 3$. & 1.34 & 22.17 & 4.20 & 741 & 0.47 & 2.33 & 1.87 & 78.76 \\
\hline $\mathrm{TiO}_{2} / \mathrm{Cr}(\mathrm{WI}) 5.0$ & 1.82 & 21.42 & 3.91 & 791 & 0.45 & 2.32 & 1.59 & 66.52 \\
\hline $\mathrm{Cr}(\mathrm{DI}) 1.5$ & 1.27 & - & 4.07 & 1136 & 1.11 & 2.75 & 1.32 & 23.78 \\
\hline $\mathrm{Cr}(\mathrm{DI}) 2.0$ & 1.48 & - & 3.94 & 980 & 0.94 & 2.52 & 1.42 & 23.95 \\
\hline $\mathrm{Cr}(\mathrm{DI}) 4.5$ & 3.21 & - & 4.15 & 777 & 0.90 & 2.56 & 1.59 & 23.78 \\
\hline $\mathrm{TiO}_{2} / \mathrm{Cr}(\mathrm{DI}) 1.5$ & 0.81 & 23.06 & 4.22 & 695 & 0.64 & 2.74 & 1.48 & 71.04 \\
\hline $\mathrm{TiO}_{2} / \mathrm{Cr}(\mathrm{DI}) 2.0$ & 0.89 & 24.78 & 4.16 & 740 & 0.64 & 2.65 & 1.51 & 77.91 \\
\hline $\mathrm{TiO}_{2} / \mathrm{Cr}(\mathrm{DI}) 4.5$ & 1.88 & 25.70 & 4.32 & 690 & 0.70 & 2.57 & 1.75 & 64.17 \\
\hline
\end{tabular}

${ }^{\mathrm{a}}$ Metal content by FRX, $\left.{ }^{\mathrm{b}} a_{0}=(2 / \sqrt{ } 3) d_{100}\right)$, ${ }^{\mathrm{c}}$ Surface area (BET), ${ }^{\mathrm{d}}$ Pore volume, ${ }^{\mathrm{e}}$ Pore diameter $(\mathrm{BJH}),{ }^{\mathrm{f}}$ Wall thickness: $t w=a_{0}-D p$.

titania has been deposited on the $\mathrm{Cr}(\mathrm{WI}) \mathrm{x}$ and $\mathrm{Cr}(\mathrm{DI}) \mathrm{x}$ samples, the sharply decrease in the specific surface and pore volume can be associated with the presence of highly dispersed titania species and bigger size $\mathrm{TiO}_{2}$ nano-particles that could be blocking the pores of the structure. Moreover, the loading of $\mathrm{TiO}_{2}$ results in an increase in the wall thickness for all of the samples. This observation indicates that the chromium species finely dispersed inside the mesoporous channels and the small-size nanoparticles of chromium oxide on the external surface (detected by XRD) are not obstructing the Ti diffusion into the channels. Therefore, these results permit us to consider the existence of titanium species on the inner surface of the channels which could interact with the species of $\mathrm{Cr}$ present there.

As was explained, the presence of different chromium species can be inferred by UV-Vis DR spectroscopy. Figure 3 spectra showed that mainly $\mathrm{Cr}^{6+}$ species are present in samples synthesized by both methods (absorption range of 200-400 nm). ${ }^{29,30,32}$

Nevertheless, the increase in the $\mathrm{Cr}^{3+}$ species amount when the Cr content increased (absorption above $400 \mathrm{~nm}$ ) is clear. This fact is
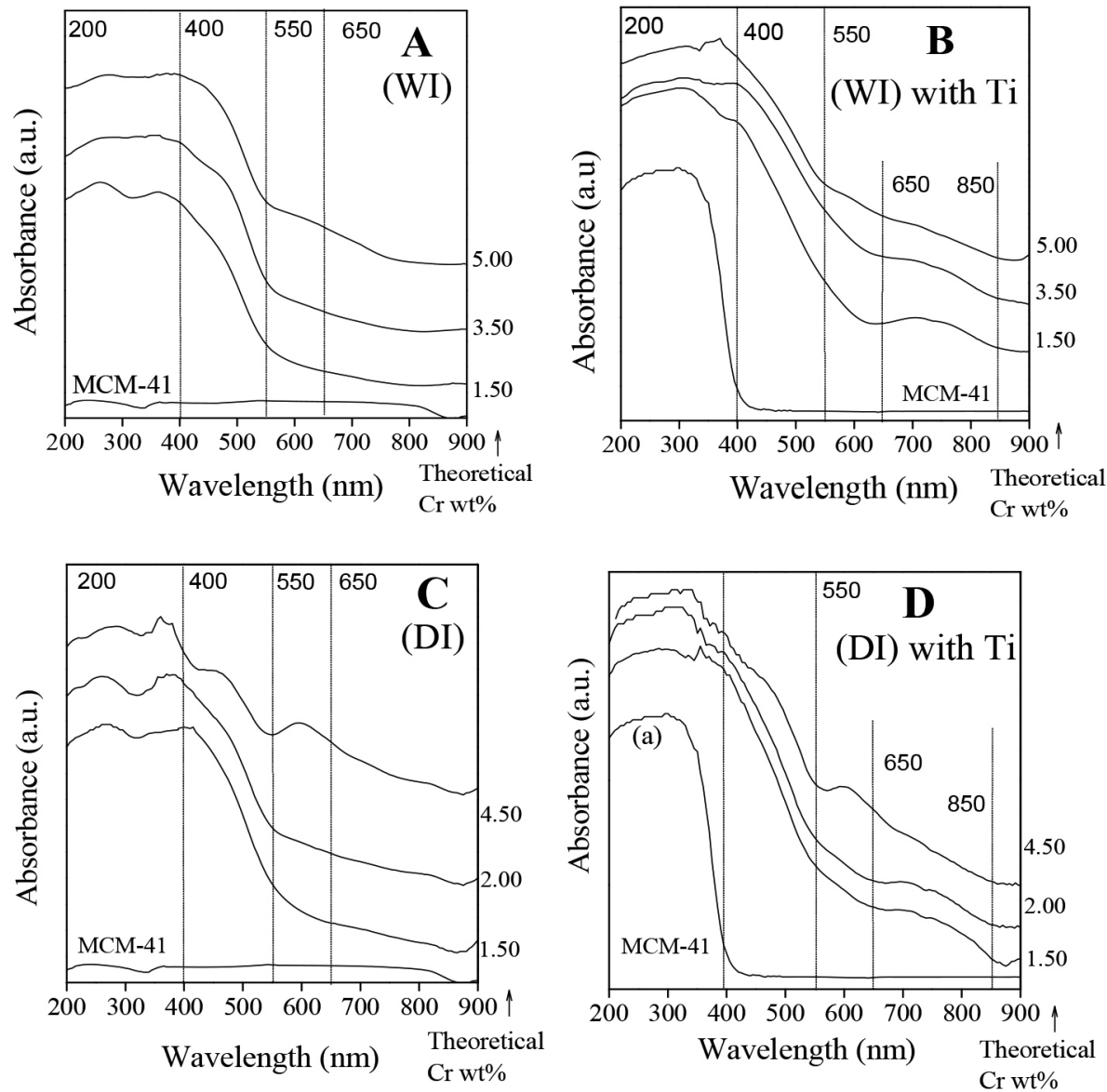

Figure 3. UV-Vis DR spectra of the samples synthesized by WI: A) modify with $\mathrm{Cr}$, B) modified with $\mathrm{Cr}$ and Ti and samples synthesized by DI, $\boldsymbol{C}$ ) modify with $\mathrm{Cr}, \mathrm{D})$ modified with $\mathrm{Cr}$ and $\mathrm{Ti}$ 
Table 2. XPS binding energy values and Surface concentration for the synthetized samples

\begin{tabular}{|c|c|c|c|c|c|c|c|c|c|}
\hline \multirow[b]{2}{*}{ Muestra } & \multicolumn{2}{|c|}{ Cr 2p $p_{3 / 2} B E(e V)^{a}$} & \multicolumn{3}{|c|}{ O 1s BE $(\mathrm{eV})^{\mathrm{a}}$} & \multicolumn{2}{|c|}{$\mathrm{Cr} / \mathrm{Si}$ atomic ratios } & \multicolumn{2}{|c|}{ Cr concentration } \\
\hline & $\mathrm{Cr}^{6+}$ & $\mathrm{Cr}^{3+}$ & $\mathrm{CrO}_{\mathrm{x}}$ & $\mathrm{TiO}_{2}$ & $\mathrm{SiO}_{2}$ & $\begin{array}{c}\text { Surface by } \\
\text { XPS }\end{array}$ & $\begin{array}{c}\text { Bulk by } \\
\text { XRF }\end{array}$ & $\begin{array}{c}\text { Surface (\%at) } \\
\text { (XPS) }\end{array}$ & $\begin{array}{l}\text { Bulk (wt.\%) } \\
\text { (XRF) }\end{array}$ \\
\hline $\mathrm{Cr}(\mathrm{WI}) 1.5$ & $579.7(29)$ & $576.1(71)$ & - & - & $532.8(100)$ & 0.023 & 0.024 & 0.73 & 0.89 \\
\hline $\mathrm{Cr}(\mathrm{WI}) 5.0$ & - & $576.5(100)$ & - & - & $532.8(100)$ & 0.027 & 0.083 & 0.87 & 2.90 \\
\hline $\mathrm{TiO}_{2} / \mathrm{Cr}(\mathrm{WI}) 1.5$ & - & $577.0(100)$ & $529.8(47)$ & $531.9(13)$ & $533.3(40)$ & 1.093 & 0.019 & 15.88 & 0.55 \\
\hline $\mathrm{TiO}_{2} / \mathrm{Cr}(\mathrm{WI}) 5.0$ & - & $576.6(100)$ & $529.9(47)$ & $532.1(23)$ & $533.5(30)$ & 0.331 & 0.064 & 6.38 & 1.83 \\
\hline $\mathrm{Cr}(\mathrm{DI}) 1.5$ & $581.4(17)$ & $577.9(83)$ & - & - & $534.1(100)$ & 0.038 & 0.034 & 1.19 & 1.27 \\
\hline $\mathrm{Cr}(\mathrm{DI}) 4.5$ & $580.2(23)$ & $576.9(77)$ & $530.4(5)$ & - & $533(95)$ & 0.074 & 0.090 & 5.27 & 3.21 \\
\hline $\mathrm{TiO}_{2} / \mathrm{Cr}(\mathrm{DI}) 1.5$ & $580.9(19)$ & $577.1(81)$ & $528.1(5)$ & $529.9(56)$ & $532.6(39)$ & 0.640 & 0.022 & 2.28 & 0.81 \\
\hline $\mathrm{TiO}_{2} / \mathrm{Cr}(\mathrm{DI}) 4.5$ & $580.5(23)$ & $576.9(77)$ & $529.7(48)$ & - & $533.1(51)$ & 0.310 & 0.049 & 4.75 & 1.88 \\
\hline
\end{tabular}

a Between brackets figure the corresponding species percentage.

evident for the $\mathrm{Cr}(\mathrm{DI}) 4.5$ sample due to the increase in the absorption at wavelengths higher than $550 \mathrm{~nm}$ and its intense green color. Moreover, a spectral response slightly shifted into red for the $\mathrm{Cr}(\mathrm{WI}) 5$ sample could account for the greater particle size of the oxides present, in agreement with its XRD pattern. In order to enhance the absorption capability of the solids, they were modified with Ti. Then, in the UVVis DR spectra, it was possible to observe an increased absorption in the UV range due to the presence of titania. Moreover, the ability to absorb in the ranges of $\sim 370-500 \mathrm{~nm}$ and $\sim 650-850 \mathrm{~nm}$ was related to a $\mathrm{Ti}$ and $\mathrm{Cr}$ species heterojunction. This effect, however, is almost negligible for the sample impregnated with the higher $\mathrm{Cr}$ content. ${ }^{30,32}$

The XPS analysis has been employed to obtain information concerning the superficial composition of catalysts, the chemical state of the constituent elements and the chromium dispersion. The Si $2 p$ binding energy value for all of the samples is around 103.4 $\mathrm{eV}$, which is characteristic of MCM-41 silica. The binding energy values of the core level $\mathrm{O} 1 s$ and $\mathrm{Cr} 2 p$ signals are shown in Table 2. As it can be observed in this Table, the photoemission $\mathrm{O} 1 s$ for the $\mathrm{Cr}(\mathrm{WI}) \mathrm{x}$ and $\mathrm{Cr}(\mathrm{DI}) \mathrm{x}$ samples is mainly due to the contribution of oxygen from silica.

Table 2 also lists the surface $\mathrm{Cr} / \mathrm{Si}$ atomic ratio determined by XPS and the bulk $\mathrm{Cr} / \mathrm{Si}$ ratio determined by XRF (X-Ray Fluorescence) for all of the synthesized catalysts. Generally, the surface $\mathrm{Cr} / \mathrm{Si}$ atomic ratio can be considered as the relative dispersion of transition metal ions on the structure of porous supports. For the $\mathrm{Cr}(\mathrm{WI})(\mathrm{x})$ and $\mathrm{Cr}(\mathrm{DI})$ $\mathrm{x}$ samples, the surface $\mathrm{Cr} / \mathrm{Si}$ atomic ratio increases with an increase in the bulk $\mathrm{Cr} / \mathrm{Si}$ ratio in the catalyst, and for most samples the values on surface and bulk are very similar, indicating the presence of the $\mathrm{Cr}$ species on the surface. Nevertheless, for the $\mathrm{Cr}(\mathrm{WI}) 5$ sample this ratio is lower than the corresponding bulk $\mathrm{Cr} / \mathrm{Si}$ ratio, indicating that the $\mathrm{Cr}$ atoms would be mostly incorporated inside the mesopores.

Only for samples modified with Ti appears also the contribution in the surface of oxygen from chromium oxide and from titania. In this sense, the surface $\mathrm{Cr} / \mathrm{Si}$ ratio notably increases for the $\mathrm{TiO}_{2}$ loaded samples. This fact indicates that the Ti loading changes the surface composition of the samples probably due to the enhancement of the surface mobility, surface arrangement and segregation of chromia onto the surface caused by the migration of extraframework chromium away from the interface.

On the other hand, for both synthesis methods, when Ti is also present in the structure, it was observed a decrease in the surface $\mathrm{Cr} /$ $\mathrm{Si}$ ratio with the incremented bulk $\mathrm{Cr} / \mathrm{Si}$ ratio as a consequence of the heterogeneous character of catalyst by the migration of surface $\mathrm{Cr}$ species and formation of $\alpha-\mathrm{Cr}_{2} \mathrm{O}_{3}$ as a segregated phase.

The $\mathrm{Cr} 2 p$ core level photoelectron profiles for all of the synthesized samples are shown in Figure 4.

The samples show two different $\mathrm{Cr}$ species or chemical states on these catalyst surfaces. The lowest binding energy contribution around $576.5 \mathrm{eV}$ is assigned to $\mathrm{Cr}^{3+}$ and the highest binding energy contribution at around $579.5 \mathrm{eV}$ corresponds to $\mathrm{Cr}^{6+}$. With respect to the samples only modified with $\mathrm{Cr}$, for the $\mathrm{Cr}$ (WI)1.5 and both $\mathrm{Cr}(\mathrm{DI})$ $\mathrm{x}$ samples, $\mathrm{Cr}^{6+}$ species can be seen on the surface. This observation could be associated with the fact that the DI method allows a higher dispersion of the $\mathrm{Cr}$ species even for the high loading. Instead, for
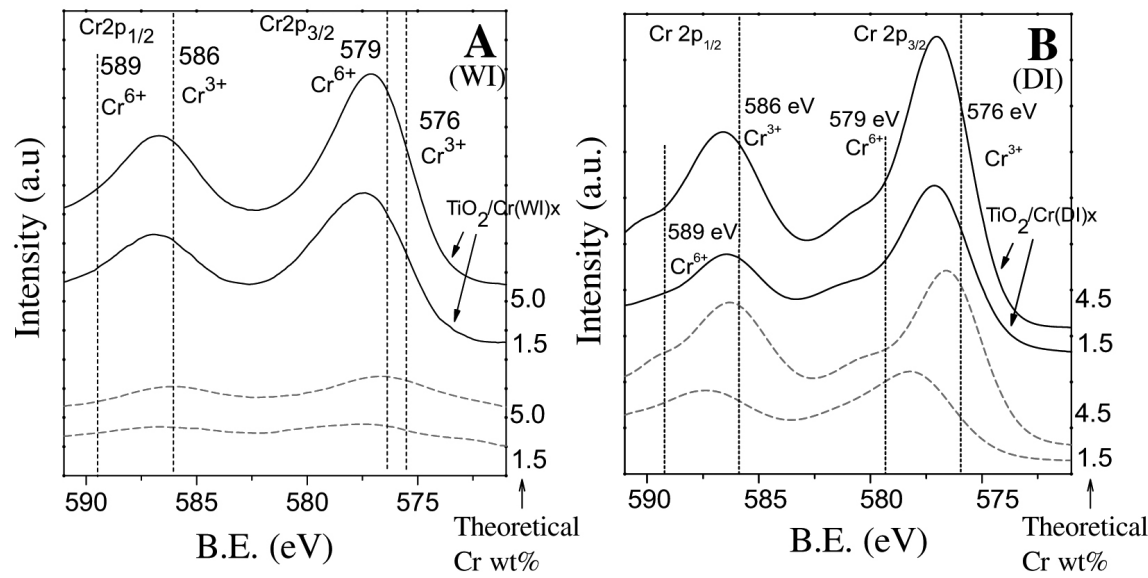

Figure 4. Cr2p core level photoelectron profile of: A) Samples synthesized by WI: (---) $\mathrm{Cr}(\mathrm{WI}) x$, (-) $\mathrm{TiO}_{2} / \mathrm{Cr}(\mathrm{WI}) x$ and $\left.\boldsymbol{B}\right)$ samples synthesized by DI: (---) $\mathrm{Cr}(\mathrm{DI}) \mathrm{x},(-) \mathrm{TiO}_{2} / \mathrm{Cr}(\mathrm{DI}) \mathrm{x}$ 
the WI method, the higher $\mathrm{Cr}$ loading results in the main formation of $\mathrm{Cr}^{3+}$ species in the catalyst surface. Finally, after the Ti loading, only the spectra of the $\mathrm{TiO}_{2} / \mathrm{Cr}(\mathrm{DI}) \mathrm{x}$ samples show the presence of surface $\mathrm{Cr}^{6+}$ species, giving evidence that the DI method favors the presence of these species highly dispersed on the surface and capable to interact with Ti leading to the desired heteroconjuntion effect.

Table 1 and Figure 5 show the $\mathrm{X}_{\mathrm{AO} 7}$ using visible radiation and the catalysts synthesized by the two methods presented in this work. $\mathrm{Cr}-$ modified MCM-41 photocatalysts show different behavior depending on the metal incorporation method used. It is clearly seen that, for similar $\mathrm{Cr}$ contents, samples synthesized by DI show significantly lower $\mathrm{X}_{\mathrm{AO} 7}$ than samples synthesized by WI. These results could be attributed to the fact that, although the isolated $\mathrm{Cr}^{6+}$ species are present in all samples, some of them would probably be located inside the mesopore wall of $\mathrm{Cr}(\mathrm{DI}) \mathrm{x}$ samples. ${ }^{35}$ Meanwhile, WI would give rise to a higher proportion of these active species located on the surface of the mesopore walls. ${ }^{30}$ However, in the case of $\mathrm{Cr}(\mathrm{DI}) \mathrm{x}$ samples, the $\mathrm{X}_{\mathrm{AO} 7}$ is practically constant for all the $\mathrm{Cr}$ contents, which could be evidencing that, although the $\mathrm{Cr}$ content increases, the limit of active species incorporation into the framework has already been reached.

Meanwhile, for $\mathrm{Cr}(\mathrm{WI}) \mathrm{x}$ samples, the catalytic activity increased as the $\mathrm{Cr}$ loading increased until the saturation coverage of the surface was reached and then remained almost constant when the inactive $\mathrm{Cr}^{3+}$ species started to appear on the surface. ${ }^{30}$ Then, both methods show similar behavior at lower metal content. The fact that the smaller $\mathrm{Cr}$ content samples result in the reported AO7 degradation accounts for the increased efficiency for the metal present in these solids due to their high dispersion, which enhances the availability of $\mathrm{Cr}^{6+}$ species. Moreover, it can also be observed in Table 1 that the $\mathrm{TiO}_{2} / \mathrm{MCM}-41$ sample showed an activity of around $10 \%{ }^{29}$ Meanwhile, the presence of both metals ( $\mathrm{Cr}$ and $\mathrm{Ti}$ ) allows increasing the $\mathrm{X}_{\mathrm{AO} 7}$ due to a synergistic effect between them. It was already reported by us that this synergism is based on the formation of electron/hole pairs in the loaded $\mathrm{TiO}_{2}$ promoted by the presence of tetrahedrally coordinated $\mathrm{Cr}^{6+}$ ions. The next transition under visible light $\mathrm{Cr}^{6+}-\mathrm{O}^{2-} \leftrightarrow \mathrm{Cr}^{5+}-\mathrm{O}^{1-}$ would take place on the catalyst surface, and would allow $\mathrm{O}^{1-}$ to scavenge electrons from the valence band of titania and $\mathrm{Cr}^{5+}$ to release electrons to the conduction band, allowing the formation of electron/hole pairs in titania, but with lower energy light $(\lambda>380 \mathrm{~nm}) .{ }^{30}$ These pairs can interact with surface hydroxyl groups on MCM-41 or adsorbed oxygen to produce highly reactive radical species that can initiate the dye photocatalytic degradation. ${ }^{31}$

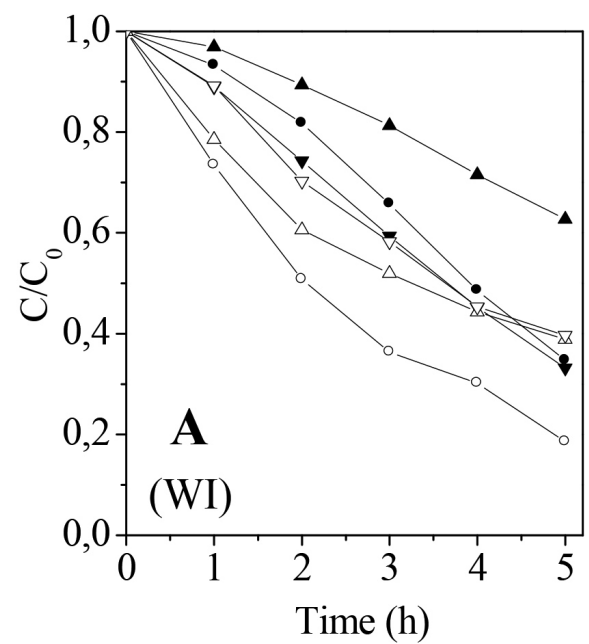

Comparing this synergistic effect for the solids obtained with both $\mathrm{Cr}$ incorporation methods, it could be observed that after the $\mathrm{Ti}$ loading, all the $\mathrm{Cr}(\mathrm{DI}) \mathrm{x}$ catalysts exhibit a large increase in activity, which evidences a strong heterojunction effect between the Ti and $\mathrm{Cr}^{6+}$ species. Thus, DI probably leads to isolated $\mathrm{Cr}^{6+}$ species highly dispersed and accessible to interact with the Ti species. Moreover, the thickening of the pore walls, after the Ti loading, gives evidence of the Ti species diffusion inside the mesopores allowing this interaction. Nevertheless, $\mathrm{TiO}_{2} \mathrm{Cr}(\mathrm{DI}) 4.5$ shows activity slightly lower than that of the other samples modified by DI, probably due to the increased presence of $\mathrm{Cr}$ species in its lower oxidation state, which would partially hinder this heterojunction. However, this synergism is less pronounced for the $\mathrm{TiO}_{2} \mathrm{Cr}(\mathrm{WI}) \mathrm{x}$ samples, being absent for the higher $\mathrm{Cr}$ content. As was explained, chromia nanoparticles of larger size can block the access of Ti species into the mesopores avoiding the desired heterojunction effect. ${ }^{30}$ Thus, DI, in comparison with WI, produces materials that allow a more efficient interaction between the $\mathrm{Ti}$ and $\mathrm{Cr}^{6+}$ species and consequently, a better use of visible radiation. This feature can be attributed to the higher $\mathrm{Cr}^{6+}$ species dispersion that, besides, would be more accessible due to the presence of oxide clusters or nanoparticles of smaller size.

On the other hand, it is known that the use of $\mathrm{Cr}$ is controversial for environmental applications. Then, in order to discard the presence of this metal in the mixture reaction, measurements of the $\mathrm{Cr}$ concentration were made by ICP. It is important to note that for the solids synthetized by the two methods, the Ti loading decreased Cr lixiviation by around $90 \%$, corroborating the importance of the presence of $\mathrm{Ti}$ in these solids.

\section{CONCLUSIONS}

Well-ordered Cr-modified MCM-41 structures with high specific areas were synthesized by two synthesis methods. All the solids exhibit mainly $\mathrm{Cr}^{6+}$ species (monochromates and di/polychromates), as well as $\mathrm{Cr}^{3+}$ species, as clusters and chromia nanoparticles that increase with the $\mathrm{Cr}$ content. The DI method, compared with the WI one, seems to give rise to a certain amount of isolated $\mathrm{Cr}^{6+}$ species located inside the mesopore walls and hence not accessible to radiation. Nevertheless, the high dispersion of the portion of these active species located on the surface of the mesopore walls, as well as the smaller size of the $\mathrm{Cr}^{3+}$ species, allows a stronger interaction between the $\mathrm{Ti}$ and $\mathrm{Cr}^{6+}$ species after the Ti loading. Thus, Ti species can easily

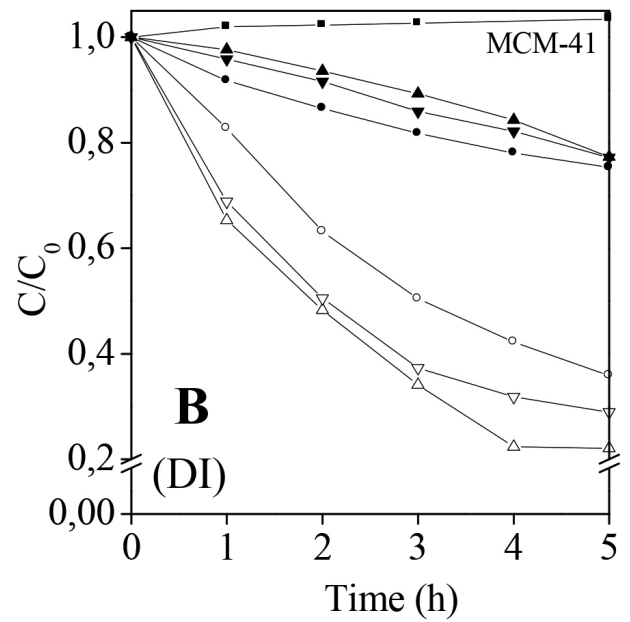

Figure 5. Variation of the normalized concentration of AO7 as a function of irradiation time. A) Samples synthesized by WI: $\mathbf{\Delta} C r(W I)(1.5)$, $\bullet \mathrm{Cr}(\mathrm{WI}) 3.5$, $\boldsymbol{\nabla} \mathrm{Cr}(\mathrm{WI}) 5.0, \Delta \mathrm{TiO}_{2} / \mathrm{Cr}(\mathrm{WI}) 1.5, \mathrm{O} \mathrm{TiO}_{2} / \mathrm{Cr}(\mathrm{WI}) 3.5, \nabla \mathrm{TiO} / \mathrm{Cr}(\mathrm{WI}) 5.0$ and $\left.\boldsymbol{B}\right)$ samples synthesized by $\mathrm{DI}: \mathbf{\Delta} \mathrm{Cr}(\mathrm{DI}) 1.5, \bullet \mathrm{Cr}(\mathrm{DI}) 2.0, \mathbf{\nabla} \mathrm{Cr}(\mathrm{DI}) 4.5, \Delta \mathrm{TiO} /$ $\mathrm{Cr}(\mathrm{DI}) 1.5, \mathrm{O} \mathrm{TiO}_{2} / \mathrm{Cr}(\mathrm{DI}) 2.0, \nabla \mathrm{TiO}_{2} / \mathrm{Cr}(\mathrm{DI}) 4.5$ 
diffuse inside the channels and give rise to a heterojunction effect leading to a markedly enhanced photoactivity (increased $\mathrm{X}_{\mathrm{AO} 7}$ ) for $\mathrm{TiO}_{2} \mathrm{Cr}(\mathrm{DI}) \mathrm{x}$ samples. Meanwhile, bigger oxide species generated by WI would be responsible for the lower heterojunction effect as well as for its absence in the $\mathrm{TiO}_{2} \mathrm{Cr}(\mathrm{WI}) 5$ sample.

\section{ACKNOWLEDGEMENTS}

V. E., S. C. and G. E. thank CONICET and UTN-FRC of Argentina for their financial support.

\section{REFERENCES}

1. Mills, A.; Davies, R. H.; Worsley, D.; Chem. Soc. Rev. 1993, 22, 417

2. Hoffmann, M. R.; Martin, S. T.; Choi, W.; Bahnemann, D. W.; Chem. Rev. 1995, 95, 69.

3. Hu, C.; Tang, Y.; Jiang, Z.; Hao, Z.; Tang, H.; Wong, P. K.; Appl. Catal. A. 2003, 253, 389 .

4. Herrmann, J. M.; Disdier, J.; Pichat, P.; Malato, S.; Blanco, J.; Appl. Catal. B. 1998, 17, 15.

5. Konstantinou, I. K.; Albanis, T. A.; Appl. Catal. B. 2004, 49, 1.

6. Segura, Y.; Cool, P.; Van Der Voort, P.; Mees, F.; Meynen, V.; Vansant, E. F.; J. Phys. Chem. B 2004, 108, 3794.

7. Reddy, E. P.; Sun, B.; Smirniotis, P. G.; J. Phys. Chem. B 2004, 108, 17198.

8. Pozzo, R.; Baltanás, M.; Cassano, A.; Catal. Today 1997, 39, 219.

9. Davydov, L.; Reddy, E.; France, P.; Smirniotis, P.; J. Catal. 2001, 203 , 157.

10. Wang, X.; Lian, W.; Fu, X.; Basset, J-M; Lefebvre, F.; J. Catal. 2006, $238,13$.

11. Higashimoto, S.; Hu, Y.; Tsumura, R.; Iino, K.; Matsuoka, M.; Yamashita, H.; Gun Shul, Y.; Che, M.; Anpo, M.; J. Catal. 2005, 235, 272.

12. Marques, F.; Canela, M.; Stumbo, A.; Catal. Today 2008, 133, 594.

13. Anandan, S.; Dyes Pigm. 2008, 76, 535.

14. Shen, S.; Guo, L.; Catal. Today 2007, 129, 414.

15. Phanikrishna Sharma, M.; Durga Kumari, V.; Subrahmanyam, M.; Chemosphere 2008, 72, 644.

16. Van Grieken, R.; Aguado, J.; López-Muñoz, M.; Marugán, J.; J. Photochem. Photobiol. A 2002, 148, 315.
17. Sun, B.; Reddy, E. P.; Smirniotis, P. G.; Appl. Catal. B 2005, 57, 139.

18. Vinu, A.; Sawant, D.; Ariga, K.; Hossain, K.; Halligudi, S.; Hartmann, M.; Nomura, M.; Chem. Mater. 2005, 17, 5339.

19. Li, G.; Zhao, X. S.; Ind. Eng. Chem. Res. 2006, 45, 3569.

20. Vinu, A.; Srinivasu, P.; Miyahara, M.; Ariga, K.; J. Phys. Chem. B 2006, $110,801$.

21. Yue, Y.; Gedeon, A.; Bonardet, J.; Melosh, N.; D’Espinose, J.; Fraissard, J.; Chem. Commun. 1999, 19, 1967.

22. Li, Y.; Zhang, W.; Zhang, L.; Yang, Q.; Wei, Z.; Feng, Z.; Li, C.; J. Phys. Chem. B 2004, 108, 9739

23. Liu, Y.; Cao, Y.; Yi, N.; Feng, W.; Dai, W.; Yan, S.; He, H.; Fan, K.; J. Catal. 2004, 224, 417.

24. Hess, C.; Hoefelmeyer, J.; Tilley, T.; J. Phys. Chem. B 2004, 108, 9703.

25. Sun, Y.; Walspurger, S.; Tessonnier, J.; Louis, B.; Sommer, J.; Appl. Catal. A 2006, 300, 1.

26. Segura, Y.; Cool, P.; Van Der Voort, P.; Mees, F.; Meynen, V.; Vansant, E. F.; J. Phys. Chem. B 2004, 108, 3794.

27. Segura, Y.; Chmielarz, L.; Kustrowski, P.; Cool, P.; Dziembaj, R.; Vansant, E. F.; Appl. Catal. B 2005, 61, 69.

28. Elías, V.; Crivello, M.; Herrero, E.; Casuscelli, S.; Eimer, G.; J. NonCryst. Solids 2009, 355, 1269.

29. Elías, V.; Vaschetto, E.; Sapag, K.; Crivello, M.; Casuscelli, S.; Eimer, G.; Top. Catal 2011, 54, 277.

30. Elías, V.; Sabre, E.; Sapag, K.; Casuscelli, S.; Eimer, G.; Appl. Catal. A. 2012, 413, 280

31. Elías, V.; Vaschetto, E.; Sapag, K.; Oliva, M.; Casuscelli, S.; Eimer, G.; Catal. Today 2011, 172, 58.

32. Patterson, A.; Phys. Rev. 1939, 56, 978.

33. Elías, V.; Sabre, E.; Winkler, E.; Satuf, M.; Rodriguez-Castellón, E.; Casuscelli, S.; Eimer, G.; Microporous Mesoporous Mater. 2012, 163, 85.

34. Stylidi, M.; Kondarides, D.; Verykios, X.; Appl. Catal. B 2004, 47, 189.

35. Bauer, C.; Jacques, P.; Kalt, A.; J. Photochem. Photobiol. A 2001, 140, 87.

36. Monteagudo, J.; Durán, A.; Monteagudo, J.; Durán, A.; Chemosphere 2006, 65, 1242.

37. Rao, K.; Lavédrine, B.; Boule, P.; J. Photochem. Photobiol. A 2003, 154, 189.

38. Fernández, J.; Kiwi, J.; Lizama, C.; Freer, J.; Baeza, J.; Mansilla, H.; J. Photochem. Photobiol. A 2002, 151, 213. 